\title{
ANÁLISE DOS PRINCÍPIOS VISUAIS NO PROJETO GRÁFICO: ESTUDO DE CASO ENVOLVENDO INFOGRÁFICOS JORNALÍSTICOS
}

\author{
Hanna França Menezes \\ Universidade Federal de Campina Grande - UFCG \\ hannamenezes@gmail.com \\ José Eustáquio Rangel de Queiroz \\ Universidade Federal de Campina Grande - UFCG \\ rangeldequeiroz@gmail.com \\ rangel@computacao.ufcg.edu.br
}

Resumo: No presente artigo, objetiva-se analisar como os elementos do design gráfico influenciam a eficiência dos infográficos, do ponto de vista do uso de elementos visuais e princípios do projeto gráfico. Adotando uma abordagem qualitativa descritiva, o estudo envolve os dois infográficos brasileiros premiados em 2015, na 23a edição do Malofiej, na categoria de infográficos impressos. A partir de uma análise dos elementos gráficos, observou-se que ambos os infográficos apresentam problemas de usabilidade no tocante à legibilidade e à organização da informação. Quanto aos aspectos estéticos, apenas o segundo infográfico foi diagnosticado como pouco atrativo, devido ao uso excessivo de texto e imagens. Por fim, quanto ao conteúdo, ambos foram diagnosticados como deficientes em mostrar pontos centrais, devido à falta de equilíbrio no uso de imagens e/ou textos. Portanto, a análise permitiu constatar que, do ponto de vista da comunicação visual, a estrutura de um projeto gráfico requer um estudo mais aprofundado sobre a gama de possibilidades no uso dos elementos gráficos, de modo a promover a harmonia entre a forma e o conteúdo.

Palavras-chave: infográfico, linguagem visual, projeto gráfico.
Abstract: In this paper, we provide a study on the influence of graphic design elements on the efficiency of an infographic from the perspective of the use of visual elements and graphic design principles. By adopting a descriptive, qualitative approach, the study involves two Brazilian infographics awarded in the 23th edition of Malofiej in printed infographics category, held in 2015. Based on graphic elements, some usability problems have been identified by analysing the readability and the organization of the information. From an aesthetical perspective, only one of the infographics proved unattractive due to excessive use of text and images. As for the content, both lack in showing key points due to the lack of balance in the use of images and/or text. Therefore, the analysis showed that from a visual communication perspective, the structure of a graphic design requires further study on the range of possibilities in the use of elements that promotes harmony between 
form and content.

Palavras-chave: infographic, visual language, graphic design

\section{INTRODUÇÃO}

A Infografia tornou-se um meio prático e eficiente de aquisição da informação, quando utilizada de maneira adequada, a partir da qual propõe-se uma "nova" forma de visualização do conteúdo. Atualmente, seu emprego no gênero jornalístico informativo se dá tanto nas mídias impressas quanto digitais, o que tem proporcionado ao leitor/usuário uma nova experiência interativa com a informação.

No infográfico, podem-se identificar os mais variados elementos gráficos, e.g., formas, cor, texto, imagens, ilustrações, diagramas. Entretanto, para que tais elementos possam servir de auxílio na apresentação do conteúdo visual, faz-se necessário o conhecimento dos princípios do projeto gráfico que envolvem a legibilidade (facilidade de leitura), a leiturabilidade (facilidade de compreensão), a percepção (organização visual) e a tipografia, dentre outros (VIARO, 2015).

Sob a perspectiva do design gráfico, fundamentados nos conceitos da linguagem visual, Carvalho e Aragão (2012) definem o infográfico como uma peça gráfica que tem por objetivo comunicar uma mensagem composta por dados quantitativos, espaciais, narrativos e/ou cronológicos, constituído por elementos visuais gráficos que associa forma e conteúdo.

Nesse sentido, ao fazer uso dos elementos da linguagem visual gráfica para compor uma mensagem informativa, o infográfico pode, por meio da caracterização do contexto da informação, atuar como um modelo visual harmônico que permita ao leitor/usuário decodificar a informação.

Sendo assim, objetiva-se, no presente artigo, analisar a conformidade dos elementos visuais, presentes nos infográficos, aos princípios do projeto gráfico. A partir de uma abordagem descritiva qualitativa, apresenta-se um estudo de caso envolvendo infográficos brasileiros premiados na 23a edição do Malofiej $^{1}$, realizado em 2015.

\section{PERCEPÇÃO E MENSAGEM VISUAL NO PROJETO DE INFOGRÁFICOS}

A percepção visual está relacionada com os elementos pertinentes à capacidade, à facilidade e à rapidez necessárias à captação, à decodificação e à compreensão da informação por parte do usuário-receptor, assim como à relação deste com o signo e o contexto no qual está inserido (FILHO, 2003).

Tendo como objeto de estudo o infográfico, o papel primordial do designer é criar uma unidade visual que facilite o processo de aquisição da informação, concebendo uma organização que permita ao usuário reconhecer padrões, estabelecer relações entre elementos gráficos e identificar informações relevantes.

No desenvolvimento de infográficos, os elementos da linguagem visual apresentam-se agrupados de modo a estabelecer uma unidade informativa. Nesta perspectiva, o infográfico caracteriza-se como uma peça gráfica que pode ser constituída

1 Premios Internacionales de Infografia, criado pela Society for News Design em 1993, com o propósito de promover anualmente publicações, que apresentam peças de qualidade estética e de conteúdo. 
de vários elementos visuais, que corroborem entre si, com o objetivo de compor uma mensagem de forma clara e eficiente.

Um aspecto pertinente no desenvolvimento de infográficos jornalísticos é que estes devem ser norteados por uma série de questionamentos que compõem uma matéria. Isto é conhecido como lead e envolve usualmente questões tais como $o$ que/quem, quanto, quando, onde, como e porquê.

O lead, quando incorporado ao infográfico, ajuda a hierarquizar a informação, privilegiando as informações que devem ser instantaneamente percebidas e, portanto, tratadas graficamente de forma diferenciada.

A eficácia de tal projeto gráfico reside no quão bem os objetivos embutidos na comunicação satisfazem as perspectivas do público-alvo. Portanto, o desafio do designer é criar um projeto gráfico que seja esteticamente apropriado e visualmente atraente e que também seja funcionalmente legível, a fim de que seja efetivamente decodificado, conforme pretendido (O'CONNOR, 2013).

Sendo assim, o uso de elementos visuais deve estar apoiado nos princípios das práticas de projeto gráfico, as quais têm por objetivo aprimorar a experiência do usuário com a interface. Portanto, é importante entender a relação existente entre os elementos da linguagem gráfica e o infográfico, a fim de que seu uso seja consciente e auxilie o usuário/leitor na aquisição da informação.

\section{ELEMENTOS GRÁFICOS}

Em sua essência o infográfico é uma peça de grande apelo visual, que mescla elementos gráficos com a finalidade de comunicar forma de rápida e objetiva um conjunto específico de informações para um determinado público (LYRA, 2016). Dentre os elementos gráficos usuais na construção de infográficos, podem ser mencionados cor, forma, imagem, ilustração, escala, direção e tipografia. No presente estudo, buscou-se analisar a relação entre os infográficos e os elementos da linguagem visual e as leis da Gestalt, como forma de confrontar as ideias concebidas na Infografia e sua adequação aos princípios do projeto gráfico.

\subsection{Linguagem Visual}

Embora a comunicação visual não disponha de regras nem se fundamente em metodologias que expressem critérios para o entendimento dos modelos visuais, quando utilizada consistentemente pode proporcionar um aprendizado mais efetivo da informação. Mesmo que a linguagem verbal seja extremamente eficaz, o uso da linguagem visual não está submetido a nenhum sistema de códigos que facilite sua compreensão e, portanto, não requer um processo de decodificação que retarde o entendimento (DONDIS, 2007).

$\mathrm{Na}$ produção de infográficos, o uso de elementos da linguagem visual é recorrente. Dentre os elementos básicos da comunicação visual, Poloni (2011) destaca como mais utilizados a posição, a forma, o tamanho, o contraste, a textura, a cor e a direção.

A posição de determinado elemento gráfico está muitas vezes relacionada à consistência - quando tal elemento se repete - produzindo a sensação de conformidade e unidade da peça. A forma pode ser percebida na Infografia como um elemento de distinção entre categorias e/ou delimitação de área. Quando associada a outros 
elementos, e.g., cor e escala, a forma pode indicar quantidade, semelhança e estabelecer relações entre variáveis.

Com relação ao tamanho, um elemento gráfico pode ser considerado maior ou menor em função de sua escala, localização e cor dos elementos em seu entorno, podendo criar uma tensão, bem como uma sensação de profundidade e movimento (LUPTON; PHILLIPS, 2014).

O contraste pode ser qualquer tipo de analogia feita entre os aspectos gráficos que torna evidente as diferenças, que pode estar associado a cor, textura, forma, escala, dentre outros. A textura, assim como o contraste, também pode estar relacionada a ideia de diferenciação. Neste sentido, é importante diferenciar a textura tátil (enquanto propriedade física) da textura visual (enquanto propriedade associada à aparência). A segunda só existe como efeito óptico (WONG, 2010).

O uso da cor na infografia, enquanto elemento de informação, pode ser observado ao se rotular, representar, mensurar, quantificar, embelezar e/ou hierarquizar a informação, podendo ser extremamente eficiente na tarefa de memorização e reconhecimento da mensagem (TUFTE, 2011).

A direção, no âmbito da infografia, tem sido aplicada como forma de indicar o sentido de leitura - embora o infográfico seja considerado uma estrutura não-linear norteando a atenção do leitor/usuário para a conexão entre as partes e clareza nas etapas concebidas do infográfico. Segundo Dondis (2007, p. 60), "todas as formas direcionais são de grande importância para a intenção compositiva voltada para um efeito e um significado definidos. "

Além dos elementos supramencionados, observa-se também o uso recorrente de tipografia, ilustração e imagem. A tipografia pode ter forte impacto na apresentação e legibilidade do infográfico, o qual geralmente apresenta título, subtítulos, legendas, texto de abertura e texto de corpo. Quanto ao uso de imagem e ilustração, tais elementos são empregados na Infografia com o propósito de tornar visível parte de um conteúdo, visando-se a tornar clara a mensagem transmitida verbalmente.

A organização desses elementos em uma peça gráfica não diz respeito somente ao uso, mas, também, à conformidade com a mensagem que se deseja transmitir e como essa mensagem é decodificada pelo leitor/usuário. Portanto, é importante analisar também os mecanismos de percepção tratados na Teoria da Gestalt.

\subsection{Leis da Gestalt}

A Teoria da Gestalt, formulada a partir de vários e rigorosos experimentos, consiste em um estudo de grande contribuição para o campo da percepção, pois possibilita explicar as relações entre o sujeito e o objeto.

Conforme a teoria da Gestalt, a percepção não se dá mediante entidades individuais, mas por meio do conjunto. Conforme sugere o próprio termo, em um sentido mais amplo, Gestalt significa estrutura, padrão. Seus princípios/leis que embasam a leitura visual são: unidade, segregação, unificação, fechamento, continuidade, proximidade, semelhança e pregnância da forma.

Dentre os princípios da Gestalt, Cairo (2012) destaca que, para a análise de infográficos, aqueles que estão mais diretamente relacionados à percepção da organização são: proximidade, similaridade, unificação, continuidade e encerramento (ver descrição e exemplificação de cada um deles no Quadro 1). 
Quadro 1 - Princípios da Gestalt aplicados à Infografia

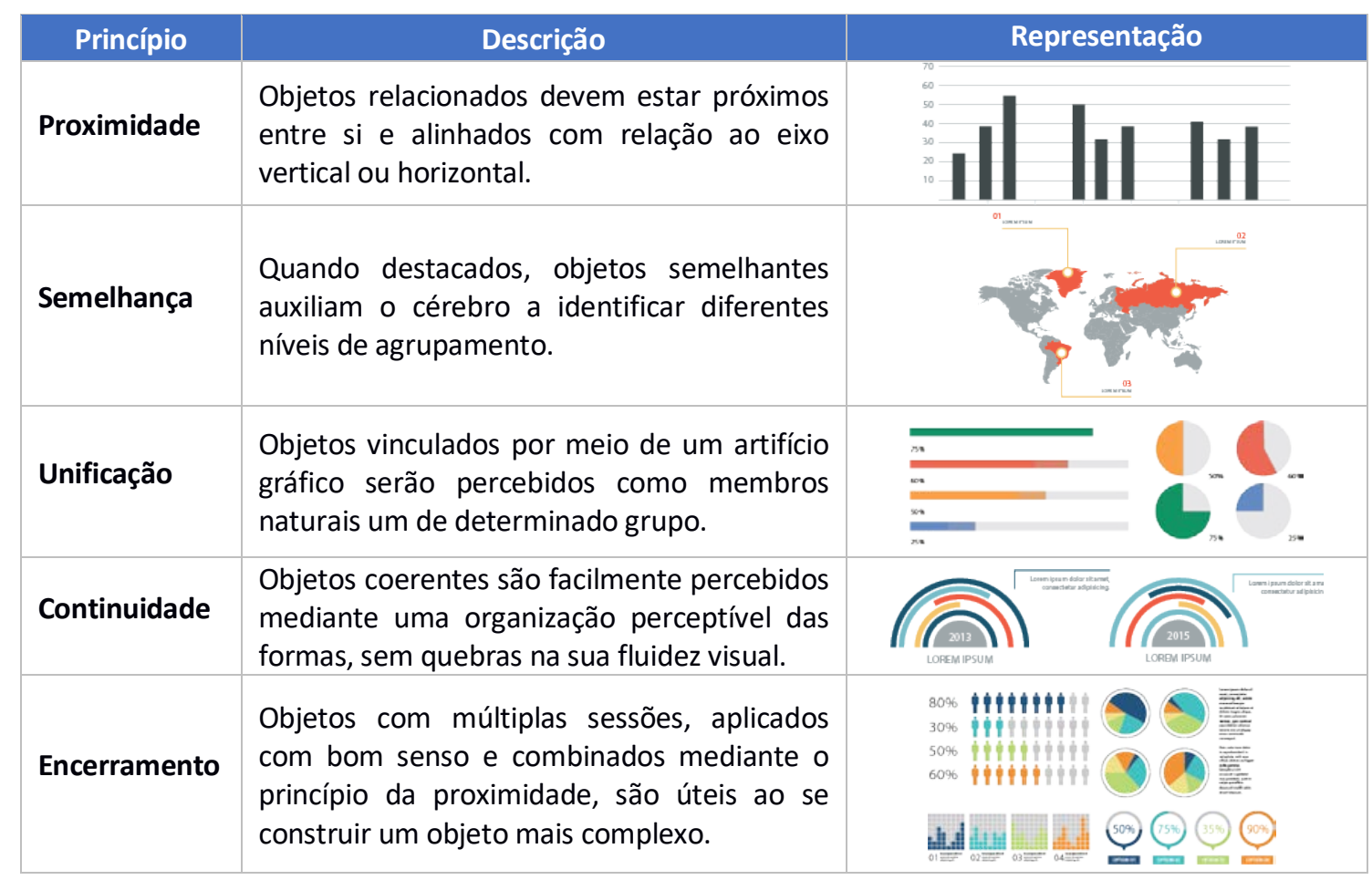

Fonte: Elaborado pelos autores, conforme Cairo (2012)

Embora exista uma grande preocupação em se determinar um modelo de concepção de infográficos, a unificação entre os elementos da linguagem visual gráfica na infografia também está associada às novas demandas das mídias, em face da modernização da comunicação e da necessidade de constante renovação dos modelos concebidos. Neste sentido, a mensagem comunicada em uma peça gráfica deve apresentar elementos que, no âmbito de uma estrutura lógica, sejam inteligíveis a qualquer leitor/usuário.

Ao analisar o processo de construção de infográficos jornalísticos, Silveira (2010) elencou um conjunto de parâmetros vinculados aos aspectos gráficos e analíticos. Contudo os aspectos analíticos - relacionados à leiturabilidade e inteligibilidade - serão tratados aqui como elementos visuais para análise de infográficos, com a finalidade de verificar a organização e conformidade destes aspectos no infográfico.

\section{MÉTODO E TÉCNICAS}

Neste estudo, adotou-se uma abordagem qualitativa descritiva, visando-se a indicar e analisar as informações presentes em infográficos. Nesse tipo de abordagem, de acordo com Gil (2008), o pesquisador familiariza-se com o problema, estuda suas características e identifica as possíveis relações entre os elementos visuais considerados. Adicionalmente, buscou-se neste estudo verificar na literatura da área indícios que caracterizassem a utilização dos princípios do projeto gráfico na concepção de infográficos.

Tendo-se como base a abordagem metodológica para a análise de infográficos adotada por Santos, Campello e Coutinho (2015), três etapas caracterizam a metodologia aqui adotada: (1) seleção do material gráfico de amostragem; (2) identificação e caracterização dos elementos visuais de análise, com base no modelo de 
caracterização proposto por Silveira (2010); e (3) análise qualitativa dos infográficos, de acordo com os elementos visuais considerados.

O estudo de caso que fundamentou a presente análise envolveu infográficos brasileiros premiados na categoria de gráficos impressos da 23a edição do Malofiej, ocorrida em março de 2015. Nessa edição, foram premiados os infográficos brasileiros $O$ Julgamento histórico (O GLOBO, 2015), na categoria de Noticias de actualidad inmediata e Por trás do véu (SUPERINTERESSANTE, 2015), na categoria Reportajes. Tendo em vista a notoriedade da análise feita pelos júris do evento, esses infográficos foram selecionados para análise por apresentarem em sua composição requisitos importantes para o estudo dos elementos visuais.

\section{ANÁLISE DE ELEMENTOS VISUAIS PRESENTES EM INFOGRÁFICOS}

A necessidade de se transformar informação textual em uma peça gráfica é o ponto de partida para a construção de um infográfico, o que requer um olhar atento para o objetivo da mensagem que se deseja transmitir. Nem toda informação necessita recorrer à linguagem gráfica, de modo que se pode tomar como base o nível de complexidade da informação de interesse, o contexto no qual esta se insere e o repertório do usuário-receptor, dentre outros.

Na presente análise, foi utilizado o conjunto de quatro elementos propostos por Silveira (2010) que deve constar em um infográfico jornalístico: integridade, usabilidade, estética e conteúdo. Cada um destes elementos se subdivide em mais três, a fim de detalhar a importância da forma e do conteúdo, conforme ilustrado na Figura 1.

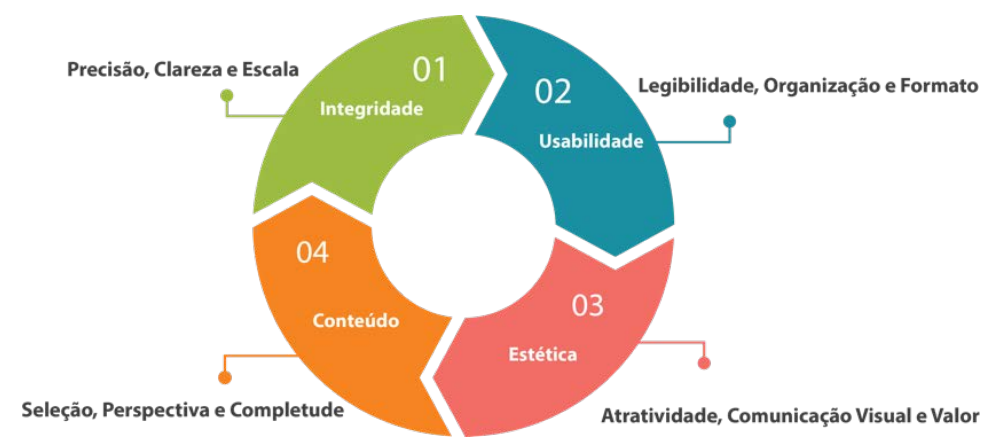

Figura 1 - Classificação das variáveis de análise para infográficos.

Fonte: Elaborado pelos autores, conforme Silveira (2010)

Para cada subelemento, foi estabelecida uma escala de zero a três, na qual zero (0) corresponde ao valor mínimo e três (3) ao valor máximo atribuído ao grau de conformidade com o parâmetro avaliado. Cada um desses elementos está associado a questões que envolvem aspectos de informação e design. Neste documento, serão analisados apenas os aspectos relacionados ao design - usabilidade, estética e conteúdo, tendo em vista que aspectos relativos à informação, por envolverem questões jornalísticas, merecem um estudo especializado que não constitui o foco desta análise.

Observa-se que a usabilidade, a estética e o conteúdo em infográficos estão associados a elementos visuais relativos à percepção da informação e à usabilidade que possibilitam a recuperação da informação de forma eficaz, eficiente e satisfatória. Além disso, tais elementos minimizam a possibilidade de leituras incorretas, evitando a frustração do leitor. 
No Quadro 2, têm-se os indicadores de usabilidade que estão diretamente relacionados à eficácia, à eficiência e à satisfação do leitor/usuário com a leitura do infográfico, em conformidade à Parte 11 do padrão internacional ISO 9241 (ISO, 1998).

Quadro 2 - Usabilidade, conforme Silveira (2010).

\begin{tabular}{|c|c|c|}
\hline Item & Descrição & Grau \\
\hline \multirow{4}{*}{$\begin{array}{l}\text { Legibilidade } \\
\text { e Percepção } \\
\text { visual }\end{array}$} & Problemas de impressão ou contraste dificultam ou impedem a leitura. & 0 \\
\hline & Há algum problema de reconhecimento gráfico, mas a leitura é pouco prejudicada. & 1 \\
\hline & Não há problemas de legibilidade ou de reconhecimento de ícones, gráficos e cores. & 2 \\
\hline & $\begin{array}{l}\text { Apresenta boa legibilidade de porções textuais e fácil reconhecimento de } \\
\text { ícones e gráficos, os quais são utilizados para organizar a informação em níveis. }\end{array}$ & 3 \\
\hline \multirow{4}{*}{ Organização } & $\begin{array}{l}\text { É difícil encontrar informações relevantes e navegar entre seções, pois faltam } \\
\text { instruções. }\end{array}$ & 0 \\
\hline & $\begin{array}{l}\text { Os pontos centrais não estão identificados de forma clara, sendo difícil } \\
\text { localizar seções de interesse específico. }\end{array}$ & 1 \\
\hline & $\begin{array}{l}\text { Apresenta boa organização para a leitura, mas sem valor hierárquico. Quando } \\
\text { se trata de uma estrutura mais complexidade gera a necessidade de instruções. }\end{array}$ & 2 \\
\hline & $\begin{array}{l}\text { A distribuição espacial de elementos gráficos facilita a leitura rápida, } \\
\text { possibilitando identificar facilmente pontos centrais e níveis de informação. }\end{array}$ & 3 \\
\hline \multirow{4}{*}{ Formato } & Formato não evidencia ou oculta dados de interesse. & 0 \\
\hline & $\begin{array}{l}\text { Escolha inadequada de formato, pois não há destaque da informação, o que } \\
\text { dificulta a leitura de níveis. }\end{array}$ & 1 \\
\hline & $\begin{array}{l}\text { Representação é adequada ao dado, mas a localização de pontos de interesse } \\
\text { deixa a desejar e tem pouco efeito na mensagem. }\end{array}$ & 2 \\
\hline & $\begin{array}{l}\text { A representação é apropriada ao dado, tornando novas informações mais } \\
\text { variáveis e destacando pontos centrais. }\end{array}$ & 3 \\
\hline
\end{tabular}

Fonte: Adaptado de Silveira (2010)

Na representação gráfica de um infográfico, a estética é também determinante, pois além de atrair a atenção do leitor/usuário, estabelece a hierarquia da informação, ao destacar informações que devem ser percebidas antes das demais. Adicionalmente, 0 conteúdo deve ser a parte central do infográfico e sua apresentação está condicionada à distribuição harmônica dos elementos visuais gráficos, que devem produzir uma interface condizente com o contexto e os objetivos da mensagem.

Vale salientar que o conteúdo deve ser a parte central do infográfico e sua apresentação está condicionada à distribuição harmônica dos elementos visuais gráficos, que devem produzir uma interface condizente com o contexto e os objetivos da mensagem.

Os Quadros 3 e 4 contêm, respectivamente, as variáveis relacionadas à estética e ao conteúdo, consideradas neste estudo. 
Quadro 3 - Estética/aparência, conforme Silveira (2010).

\begin{tabular}{|c|c|c|}
\hline Item & Descrição & Grau \\
\hline \multirow{4}{*}{ Atratividade } & $\begin{array}{l}\text { Infográfico de dimensões reduzidas e de pouco impacto visual, com } \\
\text { predominância de elementos textuais. }\end{array}$ & 0 \\
\hline & $\begin{array}{l}\text { Infográfico de impacto visual reduzido devido à maior quantidade de } \\
\text { elementos textuais. }\end{array}$ & 1 \\
\hline & $\begin{array}{l}\text { Infográfico ocupa área considerável, mas tem pouco impacto pela falta de } \\
\text { recursos visuais fortes ou pelo excesso de texto. }\end{array}$ & 2 \\
\hline & $\begin{array}{l}\text { Infográfico apresenta contraste, dimensões, ilustrações, uso adequado de cor } \\
\text { e conjunto textual moderado que atraem e fixam o olhar. }\end{array}$ & 3 \\
\hline \multirow{4}{*}{$\begin{array}{l}\text { Comunicação } \\
\text { visual }\end{array}$} & Não há uso de comunicação iconográfica. & 0 \\
\hline & $\begin{array}{l}\text { Infográfico predominantemente textual, com algumas imagens ilustrativas de } \\
\text { baixo valor de comunicação. }\end{array}$ & 1 \\
\hline & $\begin{array}{l}\text { Recursos imagéticos têm relação com o assunto, mas são genéricos e } \\
\text { discretos. }\end{array}$ & 2 \\
\hline & $\begin{array}{l}\text { O infográfico utiliza-se de cores, ícones e elementos visuais que facilitam o } \\
\text { reconhecimento do assunto e do enfoque da reportagem. }\end{array}$ & 3 \\
\hline \multirow{4}{*}{ Valor } & Produção de baixa qualidade e com problemas de reprodução ou impressão. & 0 \\
\hline & $\begin{array}{l}\text { O acabamento deixa a desejar, resultando em falhas como desalinhamento e } \\
\text { perda da identidade visual do veículo. }\end{array}$ & 1 \\
\hline & $\begin{array}{l}\text { Cuidado visual em conformidade com o projeto gráfico, mas sem } \\
\text { características espaciais que denotem valor estético único. }\end{array}$ & 2 \\
\hline & Ilustração e diagramação geram resultado de valor único. & 3 \\
\hline
\end{tabular}

Fonte: Adaptado de Silveira (2010)

Quadro 4 - Conteúdo, conforme Silveira (2010).

Seleção marginal e de pouca importância.

Deixa de apresentar os pontos mais importantes, trazendo questões

Seleção secundárias.

Apresenta dados relevantes, mas os pontos centrais são prejudicados por desvios de baixo valor noticioso.

Os pontos centrais do infográfico correspondem aos pontos centrais da reportagem ou apresentam informações relevantes aos pontos centrais.

Em vez de sumarizar, traz conteúdo longo e que não é favorecido pela apresentação escolhida.

Informação é apresentada de forma pouco visual; edição organiza o conteúdo,

Perspectivas mas tem pouco efeito na mensagem.

A informação não é suficientemente visual; poucas relações são evidenciadas.

Permite novas leituras e análises por meio dos elementos visuais da informação.

A fragmentação da mensagem compromete o seu sentido.

Completude

A fragmentação da mensagem oculta pontos centrais e reduz o interesse.

A mensagem faz sentido, mas é de baixa complexidade, pouco contextualizada, o que torna o conjunto disperso e reduzido valor do todo.

Fonte: Adaptado de Silveira (2010) 


\section{ANÁLISE DOS DADOS E DISCUSSÃO DOS RESULTADOS}

Nesta análise, foram selecionados os infográficos Por trás do véu (SUPERINTERESSANTE, 2014) e Julgamento Histórico (O GLOBO, 2014), empregados aqui como instrumentos de avaliação dos elementos visuais e sua conformidade com os princípios da Gestalt. O primeiro deles, ilustrado na Figura 2, retrata a cultura muçulmana por meio do véu - vestimenta feminina carregada de significados e tradição simbólica - e suas transformações ao longo do tempo.

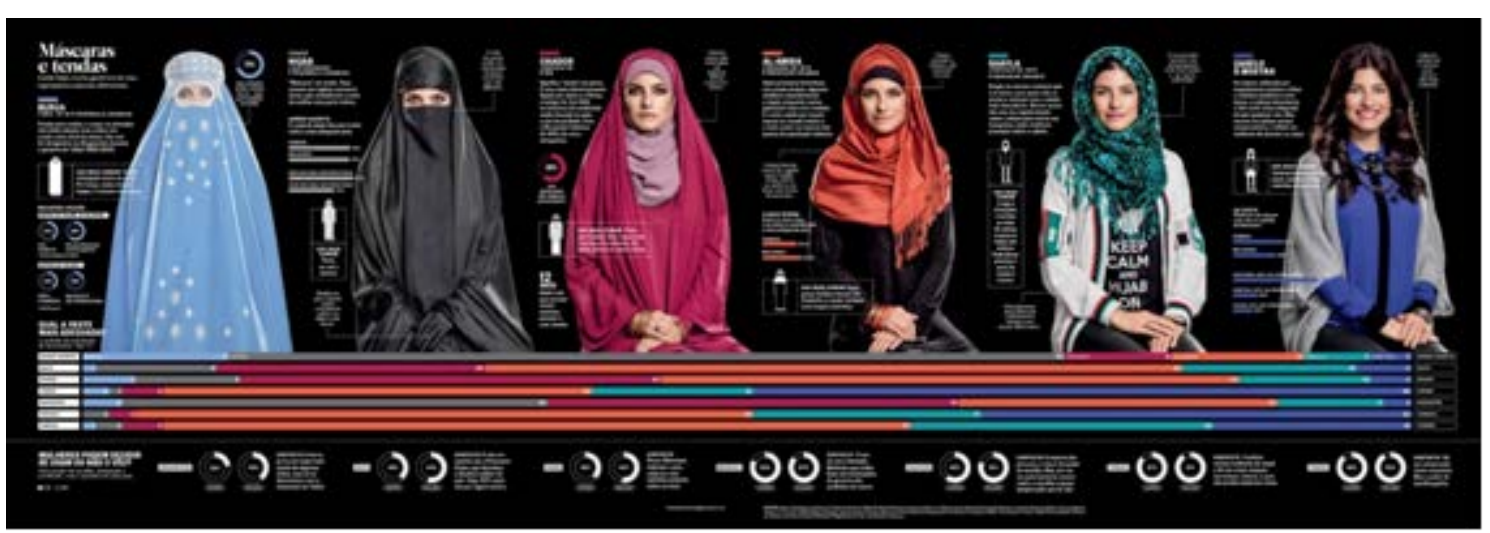

Figura 2 - Por trás do véu

Fonte: Revista Superinteressante

Com relação aos subelementos de usabilidade, verifica-se que, do ponto de vista da (i) legibilidade, a peça não apresenta graves problemas, porém a falta de balanceamento entre o texto e a imagem desfavorece o primeiro, dada a escala do segundo, o que pode comprometer o reconhecimento da informação textual; no tocante à (ii) organização, é possível fazer uma leitura da peça, porém não há um valor hierárquico; por fim, no que diz respeito ao (iii) formato, a representação é adequada ao dado, mas a localização de pontos de interesse textual deixa a desejar e tem pouco efeito na mensagem.

Sobre os aspectos estéticos, há um alto grau de (i) atratividade no uso do contraste, dimensões, cores e imagens, que atraem o leitor a fixar seu olhar no infográfico; no aspecto (ii) comunicação visual, o infográfico apresenta-se predominantemente visual, explorando o recurso imagético e cores para facilitar o reconhecimento das partes e suas relações; e no aspecto (iii) valor, o uso de imagens, ícones, cores, gráficos e texto dialogam entre si, gerando um resultado de valor único. Por fim, no tocante ao conteúdo, no aspecto (i) seleção o infográfico apresenta dados relevantes, mas os pontos centrais são prejudicados por desvios (imagens em grande escala); no aspecto (ii) perspectiva o infográfico permite novas leituras e análises por meio da visualização gráfica da informação; e no aspecto (iii) completude, a mensagem é completa, com vários níveis de informação.

Observou-se, ainda, o uso de cores que promovem uma relação de proximidade, semelhança e unificação dos demais elementos gráficos, ao relacionarem o conteúdo informativo com a vestimenta analisada. Como elemento informativo, a cor, juntamente com a forma, contribui na representação dos dados quantitativos, ao se relacionarem com o tipo de vestimenta, possibilitando a rotulação e o estabelecimento de relações comparativas dos dados. Adicionalmente, Viaro (2015) ressalta que a qualidade e o desempenho de uma peça gráfica estão diretamente relacionados ao conceito de valor de leitura, composto pelo valor estético, pela legibilidade e pela leiturabilidade. 
Contudo, é importante observar que os elementos textuais presentes na peça não têm o mesmo grau de visibilidade que as imagens, fato que pode prejudicar a leiturabilidade. Além do mais, o uso das cores empregadas na identificação da informação quantitativa, de forma redundante, torna as informações textuais secundárias. Uma síntese da pontuação para o infográfico da Figura 2, a partir da análise dos subelementos propostos por Silveira (2010), é apresentada no Quadro 5.

Quadro 5 - Síntese da pontuação para o infográfico da Figura 2.

\begin{tabular}{|l|l|c|}
\hline Elementos & Subelementos & Grau atribuído \\
\hline \multirow{3}{*}{ Usabilidade } & Legibilidade e Percepção visual & 2 \\
\cline { 2 - 3 } & Organização & 2 \\
\cline { 2 - 3 } & Formato & 2 \\
\hline \multirow{3}{*}{ Estética/aparência } & Atratividade & 3 \\
\cline { 2 - 3 } & Comunicação visual & 3 \\
\cline { 2 - 3 } & Valor & 3 \\
\hline \multirow{3}{*}{ Conteúdo } & Seleção & 2 \\
\cline { 2 - 3 } & Perspectiva & 3 \\
\hline & Completude & 3 \\
\hline
\end{tabular}

Fonte: Elaborado pelos autores, conforme Silveira (2010)

Com relação aos aspectos de usabilidade e conteúdo, observa-se, de um modo geral, que o infográfico da Figura 2 não atende plenamente aos padrões de eficácia, eficiência e satisfação do leitor/usuário, ao deixar em segundo plano a legibilidade e leiturabilidade do conteúdo. Quanto aos aspectos estéticos, observa-se, entretanto, um cuidado especial no tratamento de imagens, cores e formas, que causam uma boa impressão. Contudo, a eficácia da comunicação se deve não só aos aspectos estéticos (forma), mas também aos objetivos da mensagem (conteúdo) e à qualidade do tipo de informação que é transmitida ao leitor/usuário, a fim de que sejam satisfeitas todas as suas necessidades de informação. O segundo infográfico analisado, Julgamento Histórico, é ilustrado na Figura 3.

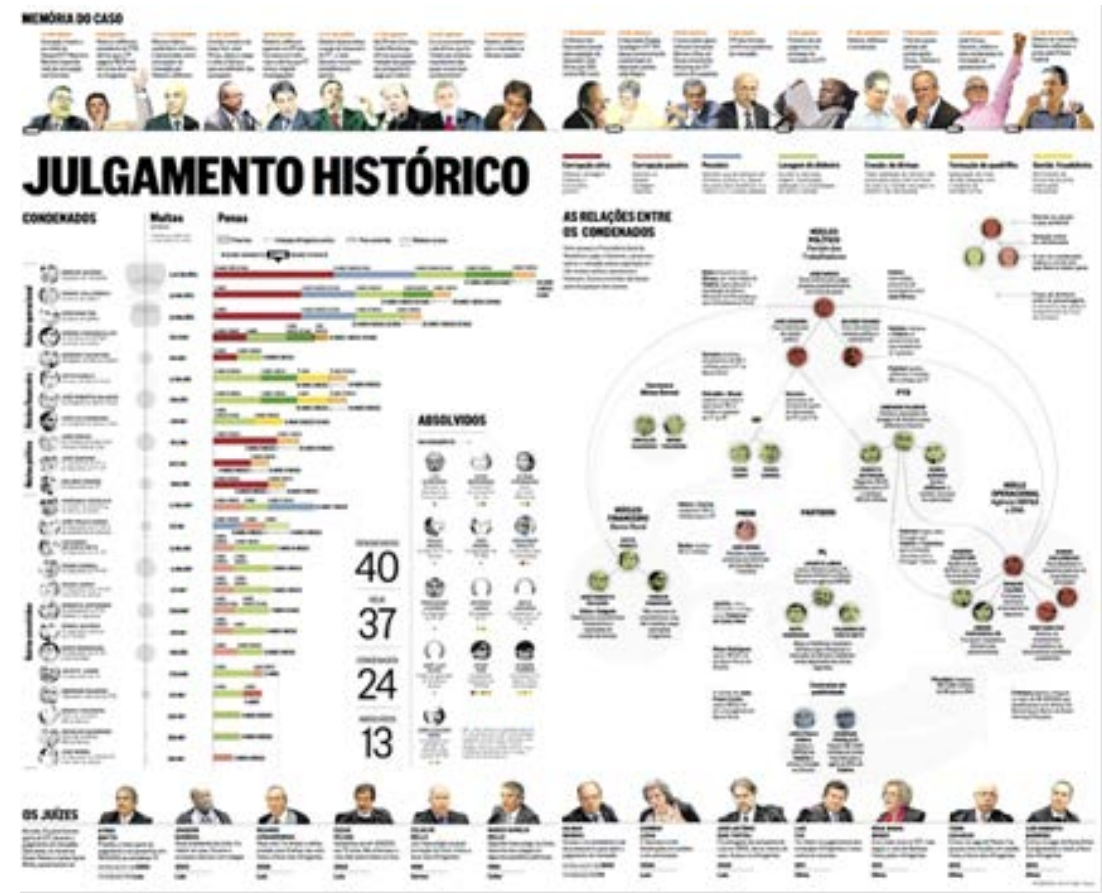

Figura 3 - Julgamento Histórico.

Fonte: Jornal O Globo 
Vencedor da medalha de prata na categoria Noticias de actualidad imediata, o infográfico da Figura 3 contém os desdobramentos e o desfecho do mensalão, ilustrando as relações entre os envolvidos, os condenados, os absorvidos, as penas aplicadas e a posição de cada juiz. Na análise da usabilidade, no tocante à (i) legibilidade visual verificase sobrecarga de informações, falta de foco e falta de balanceamento na distribuição dos elementos gráficos, o que compromete a legibilidade; quanto à (ii) organização, a grande complexidade e variedade de informações torna difícil encontrar o ponto central, assim como a distribuição espacial, legendas, cores e imagens em excesso dificulta a navegação entre as seções de diferentes níveis informacionais; por fim, em relação ao (iii) formato, a apresentação dos dados dificulta a leitura dos diferentes níveis.

Para a estética, no que concerne a (i) atratividade, o infográfico ocupa uma área considerável, mas tem pouco impacto visual, devido à quantidade excessiva de texto, imagens e formas, apresentados em escala reduzida; no tocante à (ii) comunicação visual, o infográfico apresenta-se predominantemente textual, com algumas imagens ilustrativas de baixa escala; por fim, no que diz respeito ao (iii) valor, a composição visual não se apresenta de forma agradável, sendo caracterizado pela falta de alinhamento e de direcionamento, o que promove interrupções visuais numerosas e dispêndio excessivo de tempo do usuário para estabelecer relações entre as partes do conteúdo.

$\mathrm{Na}$ análise do conteúdo, no tocante à (i) seleção, verifica-se a presença de dados relevantes, prejudicados, contudo, por desvios; quanto à (ii) perspectiva, a peça é dotada de um conteúdo extenso, que não é favorecido pela forma de apresentação escolhida; por fim, no que concerne a (iii) completude, a fragmentação da mensagem reduz o interesse e o valor do todo, devido à carga excessiva de informações.

Segundo Viaro (2015), a simplicidade de um projeto gráfico está diretamente relacionada ao processo cognitivo do leitor/usuário e contribui para a percepção, processamento e memorização do conteúdo. Quando se trata de conteúdos complexos, que envolvem grande quantidade de informações relacionadas entre si, uma alternativa a ser considerada é o uso de seções devidamente agrupadas, que façam uso de espaços livres, criando uma estrutura hierárquica (com vários níveis de leitura). Vale ressaltar também a importância de se manter a consistência, por meio de elementos visuais, que unifiquem o conteúdo, agregando um valor de unidade ao infográfico.

Uma síntese da pontuação para o infográfico da Figura 3, a partir da análise dos subelementos propostos por Silveira (2010), é apresentada no Quadro 6.

Quadro 6 - Síntese da pontuação para o infográfico da Figura 3.

\begin{tabular}{|l|l|c|}
\hline \multicolumn{1}{|c|}{ Elementos } & \multicolumn{1}{c|}{ Subelementos } & Grau atribuído \\
\hline \multirow{3}{*}{ Usabilidade } & Legibilidade e Percepção visual & 1 \\
\cline { 2 - 3 } & Organização & 1 \\
\cline { 2 - 3 } & Formato & 1 \\
\hline \multirow{2}{*}{ Estética/aparência } & Atratividade & 2 \\
\cline { 2 - 3 } & Comunicação visual & 1 \\
\cline { 2 - 3 } & Valor & 1 \\
\hline \multirow{2}{*}{ Conteúdo } & Seleção & 2 \\
\cline { 2 - 3 } & Perspectiva & 0 \\
\cline { 2 - 3 } & Completude & 1 \\
\hline
\end{tabular}

Fonte: Elaborado pelos autores, conforme Silveira (2010)

O diagnóstico do infográfico da Figura 3, apresentado a seguir mostra que houve uma preocupação excessiva em fornecer dados, em detrimento aos aspectos de usabilidade, estética e conteúdo, prejudicando a apresentação do infográfico. Observa- 
se que o baixo grau atribuído aos subelementos analisados revela que o tratamento de informações complexas requer muito mais atenção e bom senso no uso elementos visuais, dadas as relações que devem ser estabelecidas para tornar clara a mensagem. Portanto, mesmo que o conteúdo seja extenso, é possível propor uma representação visual clara, atrativa e com valor de informação. Uma estratégia recomendável é a adequação aos princípios básicos do projeto gráfico e sua conformidade com os padrões que estabelecem diretrizes fundamentais às boas práticas de projeto de interfaces.

\section{CONSIDERAÇÕES FINAIS}

Ao analisar a metodologia proposta por Silveira (2010), observou-se que, mesmo estando em níveis diferentes de classificação (numerados de zero a três), as características dos subelementos considerados mesclam-se nos infográficos analisados. Dada a combinação das características enumeradas pelo autor, foram feitas algumas adaptações, buscando-se identificar com maior precisão as especificidades de cada infográfico.

Observou-se também que, no primeiro infográfico analisado, o uso excessivo de elementos visuais dificulta a usabilidade do infográfico, pois a carga informativa elevada desfavorece a leiturabilidade e memorização dos elementos, ambos fatores importantes no processo de aquisição da informação e na satisfação do leitor/usuário ao encontrar a informação de que necessita. Outro importante aspecto analisado no segundo infográfico diz respeito à legibilidade da informação textual, disposta em escala muito inferior aos outros elementos gráficos, i.e., as informações gráficas e textuais não são balanceadas, o que pode ocasionar um desvio de foco na leitura do texto apresentado.

A análise dos infográficos mostrou que a estrutura de um projeto gráfico requer um estudo mais aprofundado sobre as possibilidades de uso dos elementos gráficos na comunicação visual, alinhados aos princípios do projeto gráfico e às Leis da Gestalt. Caso essas escolhas não estejam alinhadas com os objetivos da comunicação, seu uso tornase irrelevante, ocasionando falhas no processo de decodificação da mensagem por parte do leitor/usuário. Além dos elementos gráficos, também é importante analisar o contexto de uso, os objetivos da mensagem e como a unidade visual é percebida pelo leitor/usuário, a fim de promover equilíbrio entre forma e conteúdo.

Diante do exposto, ressalta-se a necessidade de expandir os estudos iniciados por Silveira (2010), relacionando-os e adequando-os qualitativamente aos princípios da Gestalt e ao padrão internacional ISO 9241 (ISO, 1998), que tratam com maior clareza das especificidades demandadas no processo de projeto de interfaces com usuários.

Por se tratar de um assunto complexo, que envolve a codificação e a decodificação de uma mensagem visual gráfica, entende-se também a necessidade de consultar o leitor/usuário quanto a suas reais expectativas e assimilações entre forma e conteúdo.

\section{REFERÊNCIAS}

ALVIM, A. Julgamento Final. O Globo. Rio de Janeiro, 2014.

CAIRO, A. The Functional Art: An introduction to information graphics and visualization. New Riders, 2012.

CARVALHO, J.; Aragão, I. Infografia: Conceito e Prática. InfoDesign: Revista Brasileira de

Design da Informação, 9(3), pp. 160 - 177, 2012. 
O'CONNOR, Z. Colour, contrast and gestalt theories of perception: The impact in contemporary visual communications design. Color Research \& Application, 40(1), pp. 85-92, 2015.

DONDIS, A. D. Sintaxe da Linguagem Visual. Tradução de Jefferson Luiz Camargo. 3a ed. São Paulo: Martins Fontes, 2007.

FILHO, J. G. Ergonomia do objeto: sistema técnico de leitura ergonômica. São Paulo: Escrituras Editora, 2003.

GIL, A. C. Como elaborar projetos de pesquisa. 5ạ ed. São Paulo: Atlas, 2010.

INTERNATIONAL ORGANIZATION FOR STANDARDIZATION, ISO 9241 Ergonomic Requirements for Office Work with Visual Display Terminals (VDTs) - Part 11: Usability principles. Geneva, 1998.

LIMA, R. C. O que é infografia jornalística? InfoDesign: Revista Brasileira de Design da Informação, 12(1), pp. 111-127, 2015.

LUPTON, E. Pensar com tipos: guia para designers, escritores, editores e estudantes. $2^{a}$ ed. Tradução de André Stolarski e Cristina Fino. São Paulo: Cosac Naify, 2013.

LYRA, K. T. et al. Infographics or Graphics+ Text: Which Material is Best for Robust Learning?. arXiv preprint arXiv:1605.09170, 2016.

POLONI, R. W. A infografia como ferramenta auxiliar na aprendizagem. Monografia de Conclusão de Curso - Universidade Federal do Rio Grande do Sul, Porto Alegre, RS, 2011.

SANTOS, G. M. S.; CAMPELLO, S. B.; COUTINHO, S. G. Variáveis para análise de infográficos interativos: um estudo descritivo em artefatos educacionais para o ensino médio. In: 70 Congresso Internacional de Design da Informação. Blucher Design Proceedings, Volume 2, pp. 230-242, 2015.

SILVEIRA, L. H. Y. da. Modelo de caracterização de infográficos: uma proposta para análise e aplicação jornalística. 2010. Tese de Doutorado. Universidade de São Paulo. POR TRÁS DO VÉU: As vestes islâmicas muito além da burca e do preconceito. Revista Superinteressante. São Paulo, ed. 335, 2014.

TUFTE, E. R. Envisioning information. 13a ed. Connecticut: Graphic Press, 2011. VIARO, F. S. Proposição de diretrizes para o projeto de gráficos instrucionais de qualidade. Dissertação (Mestrado) - Universidade Federal do Rio Grande do Sul, Programa de Pós-graduação em Design, Porto Alegre, RS, 2015.

WONG, W. Princípios de forma e desenho. 2ae ed. São Paulo: Martins Fontes, 2010. 